International Journal of Instruction e-ISSN: 1308-1470 • www.e-iji.net

Article submission code 20200219105008

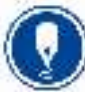

Received: $19 / 02 / 2020$ Revision: 14/09/2020
April $2021 \bullet$ Vol.14, No.2

p-ISSN: 1694-609X

pp. 305-322

Accepted: 07/10/2020

OnlineFirst: 21/01/2021

\title{
Assessment of the Role of a Private Tutor in Individual Educational Approach of a University Applicant
}

\section{Denis Bogomolov}

Corresponding author, I.M. Sechenov First Moscow State Medical University, Russia, bogomolovdenis@yahoo.com

\section{Alexandr Grinev}

I.M. Sechenov First Moscow State Medical University, Russia, grineval@ rambler.ru

\section{Iza Berechikidze}

I.M. Sechenov First Moscow State Medical University, Russia, berechikidzeiz@rambler.ru

\section{Svetlana Larina}

I.M. Sechenov First Moscow State Medical University, Russia, larinasvet@ rambler.ru

Tatyana Degtyarevskaya

I.M. Sechenov First Moscow State Medical University, Russia,

degtyarevskayata@rambler.ru

Every year a considerable number of high school graduates in Russia choose to pursue a career in medicine and apply to medical universities. However, the level of preliminary training of applicants is often insufficient to enrol in the preferred study programme. Private tutoring is often considered as a means to close the gap between the generally insufficient level of mainstream education and high entry requirements of medical universities. The study is based on the hypothesis that the tutor is an important, but not essential component of an individual educational strategy for entering a medical university. So, this paper aims to provide an analysis of the efficiency of private supplementary tuition by measuring its impact on the performance of students in the Unified State Exam (USE) in biology. Besides, the role of two educational programmes run by the Moscow government, namely, 'Medical class in Moscow school' and 'Sechenov Pre-University' is analyzed. More than 100 first-year students of Sechenov University took part in the questionnaire survey to implement the goals and objectives of the research. The survey results were analysed using Orange 3 statistical package. Standard methods of descriptive statistics, correlation analysis and clustering were used.

Keywords: applicant, high school student, individual educational strategy, medical university, tutor, private tutor, shadow education

Citation: Bogoöolov, D., Grinev, A., Berechikidze, I., Larina, S., \& Degtyarevskaya, T. (2021). Assessment of the Role of a Private Tutor in Individual Educational Approach of a University Applicant. International Journal of Instruction, 14(2), 305-322. https://doi.org/10.29333/iji.2021.14218a 


\section{INTRODUCTION}

The components' composition of individual educational strategies is an actively discussed question, both in the Russian pedagogical Society and abroad. In recent years in this area of research the world scientific community has identified several components, each of which deserves separate and more detailed discussion (Loyalka \& Zakharov, 2016; Yung, 2020). The first and most obvious point is the question of students' self-identification, the problem of their professional self-determination and the choice of further professional development trajectory. This problem is considered both at the stage of school education (Bray, 2014; Burdyak, 2015; Vasilyeva, 2016), and at the stage of transition from school education to higher education (for example Colleges or universities (Smyth, 2009) and further, in the process of studying in a higher educational institution (Gallagher, 2017).

The issues of secondary education in Russia were also considered in the article written in Higher School of Economics and Management South Ural State University, Chelyabinsk (E. V. Spiridonova, N. V. Melikhova, 2018). The article questions the secondary education quality of the first-year students who study economy. The second point of discussion is the role of tutoring in individual educational strategy building. It is obvious that such attention of the teaching community is connected also with the economic features of this type of educational services. For instance in 2010 it was clearly demonstrated that nowadays, private tutoring represents a large independent sector of the economy, which is not only actively developing but also allows a different point of view on the social stratification issues in the field of educational services (Ventura \& Jang, 2010). In addition, some researchers raise the question of correlation between the level of wealth and education of parents in families where children use the tutor services (Jung \& Lee, 2010). The problem of large, medium and small studies in the field of shadow education has been raised, many citations have been pointed out, and the main questions to this research type have been posed, however, even despite such a complete and detailed review, the question of individual educational strategies composition in the process of studying specialized, not general subjects, is still open. The author also notes the discrepancy of the data even in vast studies on this issue. Comprehensive surveys of this problem were also carried out in Bangladesh (Nath, 2008), Taiwan (Kuan, 2011), North Korea (Chan, 2019), Hong Kong (Kwok, 2009), Germany (Guill \& Lintorf, 2019), America (Buchmann et al., 2010) and Japan (Entrich, 2017).

Despite the international (including the post-Soviet space (Silova \& Bray, 2006) interest in the topic of various educational strategies, there is a lack of such studies in Russia. According to Edumarket.digital research (2016) the additional education market volume for schoolchildren in the Russian Federation amounted to 130, 3 billion rubles, and by 2021 it will reach the level of 149 billion. In international periodicals, the numerous options for educational offers provided in parallel with compulsory school education are commonly called "Shadow Education", which implies private unofficial paid educational services, due to the fact that these programs like a shadow repeat all changes in compulsory education programs. The topic of additional educational services became 
the most acutely discussed in the pedagogical community after the publication in 2014 of the article (Byun, 2014) in which the authors suggest that the lesson with a tutor in high school does not lead to a significant improvement in the knowledge of students and is, at least, optional. It is impossible to disagree with a number of conclusions proposed by the respected researchers. For example, the authors of this research support the idea that the shadow market of educational services by its development strengthens the existing social stratification and assumes unequal access to educational products for different groups of the population. However, while working at the university, and, in particular, with first-year students, it becomes obvious that most of them used the services of a tutor, preparatory courses, or both (Nurieva \& Kiselev, 2018).

The survey from Surgut Pedagogical University also discussed the role of a tutor in preparing for the Unified State Exam (Naumova, 2017). In the study, it was demonstrated that almost half of all students were engaged with a tutor at the stage of admission to the Higher school of Economics (HES.) In some works even the question of the usefulness of modern school education is raised, taking into account the fact that almost all students are studying with a tutor (Burdyak, 2015).

Despite aforesaid the authors of this research have not found works that offer to look at the issue of additional educational services in terms of their correlation with a high degree of profile orientation of education in high school. At the same time, the problem of specialized education and, in particular, chemical-biological and medical, is discussed in the literature. The questions of social and psychological adaptation of firstyear students to the loads after training in specialized classes (Kostina \& Milyaeva, 2014) are considered in detail, the question of the loads that students face while studying in classes with a high degree of specialization (Pivovarov et al., 2015) is studied. It is also worth noting that the topic of specialized education in general is also considered in scientific periodicals. For example, in one study (Vasilyeva, 2016) the researchers raise the issue of students' awareness of the profile choice and draw attention to the need to take into account the characteristics of each specific profile class. However, it is important to note that the question of the correlation of additional and school education in real individual educational strategies should be studied more carefully. As a result, with all the amount of information, both scientific and near-scientific, it is still difficult for students and their parents to decide what kind of education and class specialization should be chosen. It is also possible to consider the correlation of these components in the framework of the educational trajectory in the process of entering medical specialties at a university. The realities of modern secondary and higher education in the Russian Federation dictate the need for practical implementation of diverse, flexible and nonstandard approaches to the process of preparation for entry to higher educational institutions by high school students and their parents. It is necessary to recognize that the Unified State Exam (which is considered to be the analogue of US Scholastic Aptitude Test), in spite of certain shortcomings, plays an extremely important role in modern Russian society, equalizing the chances of applicants for admission, regardless of their place of residence, social status and, often, financial resources. 
Nowadays, high school students (and their parents) before choosing the university should take into account medium-term and long-term trends in the labour market, analyse potential for international integration of the future specialist, consider various scenarios for the practical application of their knowledge, etc. The conditions of the modern educational market dictate a more pragmatic approach to the selection of existing educational products. Just a few of the applicants choose future profession only "on the call of the heart" or "by vocation": high school students prefer to stay more mundane and pragmatic in this choice. Applicants can choose various programs of high school education or join a class with a profile orientation. In particular, in Moscow there are such successful programs as "Medical class in Moscow school", "Engineering class in Moscow school" and others. Many Russian schools have so-called "academic" classes. A common phenomenon in secondary education in the Russian Federation is specialized schools with an in-depth study of certain subjects. Moreover, in some Russian megalopolises the project "Pre-University" has been launched and is being successfully implemented. Resource centres "Sechenov Pre-University", "Pre-University of the Russian State University for the Humanities (RSUH), "Pre-University of the National Research Nuclear University Moscow Engineering Physics Institute (NRNU $\mathrm{MEPhI}$ ) and others have been successfully operating in the capital for several years. Even before admission, students get acquainted with the specific requirements of the University and have an opportunity to study at preparatory courses. In addition, traditionally in the framework of preparation for the final exam, Russian high school students choose individual lessons with a teacher, who specializes in the particular subject (private tutor). A variety of modern forms, methods and directions of education and preparation for entering the university, as well as the deliberate choice of future profession, taking into account trends in the global labour market, allows applicants to form and implement an individual educational strategy, which serves as the foundation and determines further professional activity.

"Individual educational strategy" (IES) is a planned and consistently implemented set of actions of an applicant aimed at achieving at least two goals: a) entering a predetermined university and b) formation of stronger starting positions (theoretical training, practical work skills) in relation to other first-year applicants/students.

\section{Research objectives}

As nowadays all students who want to enter the university have to pass USE, they have to choose the way of preparation that will help to perform the best results. There are several strategies that are chosen by the entrants, so it is important to evaluate each of them. This study is aimed at assessment of the tutor's role in the implementation of the applicant's individual educational strategy basing on the example of preparation for the exam in biology for admission to a medical university which is one of the most popular admission options among university entrants. In the framework of this study, various educational strategies that are implemented by the student were identified and analysed, including the students of schools participating in the program "Medical class in Moscow school" and "Sechenov Pre-university", so, it gives an opportunity to assess the effectiveness of profile orientation within the biological profile and to extrapolate 
findings to similar programs of profile orientation of education in high school. It was important to assess the effectiveness of a particular educational strategy and can help to choose the right path in preparation for admission to medical university.

So, the following objectives were formulated:

1. to reveal the dependence of Unified State Exam results on the elements of Individual educational strategy

2. to estimate the importance of shadow education for university admission

3. to assess the correlation between training in a profile class and United State Exam results

4. to compare the effectiveness of shadow education with respect to training in a profile class for university admission

\section{METHOD}

\section{Research design}

The cross-sectional design, which is a method that analyses data from a population at a specific point in time, was chosen as the methodological basis of the study. This method was chosen as it gives an opportunity to compare several representative subsets and to study heterogenic population. The actual basis of the study was a sample of anonymous questionnaires, specially prepared for this work (See Appendix). Questionnaires were randomly labelled by unique numbers. Questionnaires were collected by persons who did not participate in the study. Respondents were forbidden to sign the questionnaires and make any notes that made it possible to identify the person surveyed. All respondents were adults and agreed (verbally) to participate in survey. The questionnaire contained twelve points. Each point in the questionnaire included from two to six statements. Students were asked to choose only one of the statements in the point that, in the respondent's opinion, most accurately reflected reality.

\section{Sample and survey}

The survey was conducted among first-year students of I.M. Sechenov First Moscow State Medical University during the first semester (when all students were instructed at the department of Biology and General genetics) of 2018 - 2019 academic year. The General population was 164 respondents (at the age from 17 to 19 without sex differentiation). Students were voluntary to participate in the survey. Preliminary analysis of the obtained material showed that five questionnaires were spoiled. The content of 159 questionnaires was analysed.

This volume of the general population of respondents (up to 200 people) was chosen based on the recommendations for preliminary (pilot) sociological research in the "primary selection units", which may include the first year of medical university (Kostina \& Milyaeva, 2014).

\section{Data analysis}

Statistical processing of the obtained actual material was carried out using the statistical package Microsoft Excel for MacOS. In addition, the specialized statistical program 
Orange 3 was used for the material processing. In the framework of the study standard and advanced methods of descriptive statistics as one-way analysis of variance (the variance in the samples was calculated) and Cosine и Euclidean Distance metric were used. For all samples, the mean, standard deviation, standard error, sample variance and kurtosis were calculated. At all stages of obtained material processing the variance value was calculated (univariate analysis of variance), data correlation analysis and data clustering were used. The used methods are standard methods for the analysis of various subsets.

\section{Research limitations}

It should be emphasized that the objectives of this study did not include an evaluation of the quality of the tutor's work. The fact is that it is almost impossible to carry out such an assessment in the conditions of complete opacity of the market of individual educational services in Russia. The level of tutors training, their pedagogical skills cannot be estimated basing on the subjective perception of the surveyed students. The criterion of "price for one lesson" is also not representative, since the cost of such services varies greatly depending on the region, the regalia or rating of the tutor, etc.

The research methods used did not allow studying and formalizing the motivation of applicants.

The study compared exclusively the results of the USE. Perhaps, applying other metrics may broaden understanding of the issue.

\section{FINDINGS}

It was suggested that within the framework of the individual educational strategy implementation an applicant (and / or his parents) responsibly searched for a private teacher and, as a result, chose the most optimal option. It could be assumed that the economic and geographical factor would be one of the conditions that could affect the choice of an individual educational strategy, as well as the inclusion of a tutor in the process of preparing for the USE and entering the university. Applicants from Moscow, the Moscow region and large Russian megacities might have initially better starting positions compared to high school students living in ordinary, not large Russian cities, regional centres, urban-type settlements and villages.

The analysis of questionnaires showed that among the 159 surveyed first-year students, 73 were graduates of Moscow schools, five were graduates of secondary schools from other Russian cities, 67 students received secondary education in regional centres or in other cities of the Russian Federation, another 8 people were students of schools in urban settlements or villages, and six students received secondary education abroad.

It should be noted that the small number of students from other Russian cities, most likely could be explained by the fact that school graduates from megacities often preferred to enter local medical schools, and did not to go to study in Moscow. At the same time for school graduates from regional centres and other small cities of the Russian Federation, admission to a Moscow university was a significant (sometimes determining) step in the implementation of an individual educational strategy. 
Therefore, their number was almost equal to the number of graduates of Moscow schools. Classes with a tutor in Biology were, in fact, a prerequisite for preparation for the USE and university admission and, therefore, an important element of the IES.

According to data collected, 120 of the 159 surveyed students $(75.5 \%)$ at least once used the services of a tutor. 27 students $(22.5 \%)$ worked with a tutor for two years (1011 grades), and 61 applicants $(50.8 \%)$ were constantly engaged with a private teacher in a graduation class. 39 entrants $(24.5 \%)$ did not study with a tutor (Table 1, Figure 1).

Table 1

Private lessons with a tutor

\begin{tabular}{|c|c|c|c|c|c|}
\hline & Moscow school & $\begin{array}{l}\text { School in } \\
\text { another } \\
\text { megapolis }\end{array}$ & $\begin{array}{l}\text { Regional center / } \\
\text { other town of the } \\
\text { Russian } \\
\text { Federation }\end{array}$ & $\begin{array}{l}\text { School in the } \\
\text { urban-type } \\
\text { settlement/ } \\
\text { village/ hamlet }\end{array}$ & $\begin{array}{l}\text { Secondary } \\
\text { education outside } \\
\text { the Russian } \\
\text { Federation }\end{array}$ \\
\hline $\begin{array}{l}\text { Tutor. } \\
10-11 \text { grades. }\end{array}$ & 9 & 0 & 14 & 3 & 1 \\
\hline $\begin{array}{l}\text { Tutor. } \\
11 \text { grade. }\end{array}$ & 30 & 4 & 25 & 1 & 1 \\
\hline $\begin{array}{l}\text { Tutor. } \\
11 \text { grade. } \\
\text { Irregularly. }\end{array}$ & 8 & 0 & 6 & 1 & 1 \\
\hline $\begin{array}{l}\text { Tutor. } \\
11 \text { grade. } \\
\text { Regularly. Half of } \\
\text { a year. } \\
\end{array}$ & 7 & 0 & 4 & 0 & 0 \\
\hline $\begin{array}{l}\text { Tutor. Several } \\
\text { lessons. }\end{array}$ & 4 & 0 & 1 & 0 & 0 \\
\hline No tutor. & 15 & 1 & 17 & 3 & 3 \\
\hline
\end{tabular}

$\Sigma=159 ; P=0.002 ; \mu=5.3 ; S E=1.39 ; \sigma=7.66$

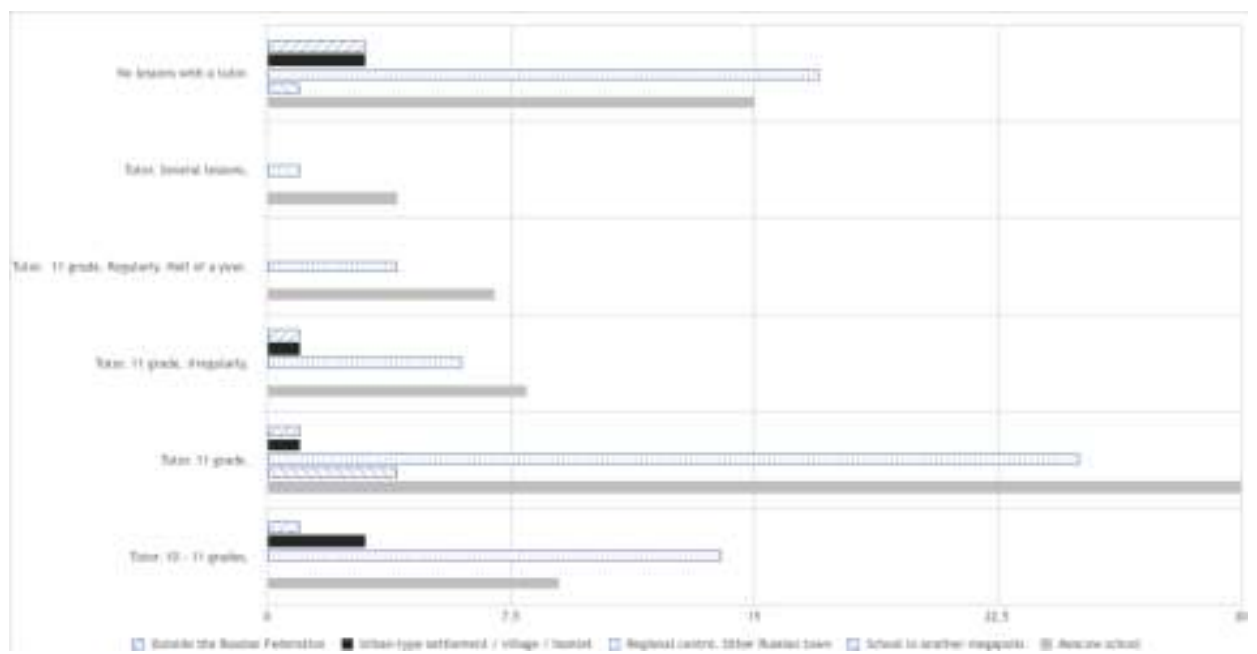

Figure 1

Private lessons with a tutor 
Regular classes in the eleventh (final) class throughout the school year were the most common (popular) option of interaction with a tutor. Apparently, classes with a tutor in the profile subject throughout the school year in the final class, from the point of view of applicants (and / or their parents), is the most optimal form of preparation for the exam. However, using the results of the exam as the main criterion for assessing the effectiveness of the tutor, the following correlation was found (Table 2).

Table 2

The dependence of the exam results on the duration of classes with a tutor (the most important pairs)

\begin{tabular}{ll}
\hline Private lessons with a tutor & Correlation value $(\mathrm{r})$ \\
\hline 11 grade; six months - & 0.971 \\
11 grade; regular classes & \\
\hline 11 grade; six months - & 0.956 \\
$\begin{array}{l}10-11 \text { grades; regular classes } \\
11 \text { grade; regular classes }-\end{array}$ & 0.932 \\
$\begin{array}{l}10-11 \text { grades; regular classes } \\
\text { No tutor }\end{array}$ & 0.462 \\
Several lessons with a tutor &
\end{tabular}

It should be noted that the results of correlation analysis largely coincided with clustering (Figure 2).

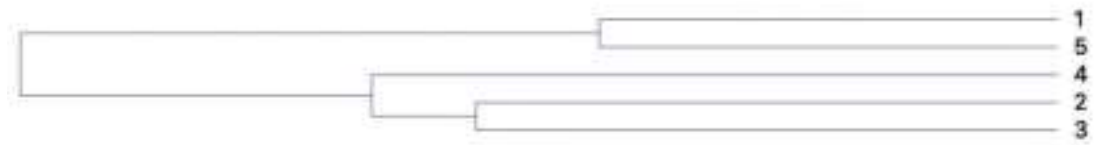

Figure 2

Clusters of USE results depending on the duration of classes with a tutor. Note: 1 Tutor. 10-11 grades; 2 - Tutor. 11 grade. Regularly; 3 -Tutor. 11 grade. Irregularly; 4 - Tutor. 11 grade / six months; 5 - Tutor. Several lessons.

Basing on the obtained results it could be assumed that with proper intensity and organization of the preparation process regular semi-annual classes with a tutor were not less effective than classes with a tutor during the whole academic year in 11th grade. Probably it is connected with the discipline level of the student and the regularity of studies is more important than the duration. Moreover, in case of the proper organization of the educational process duration of the preparation will not be so important.

A summary of the USE results and options for classes with a tutor are presented in Table 3 and in Figure 3. 
Table 3

Duration of classes with a tutor and exam results

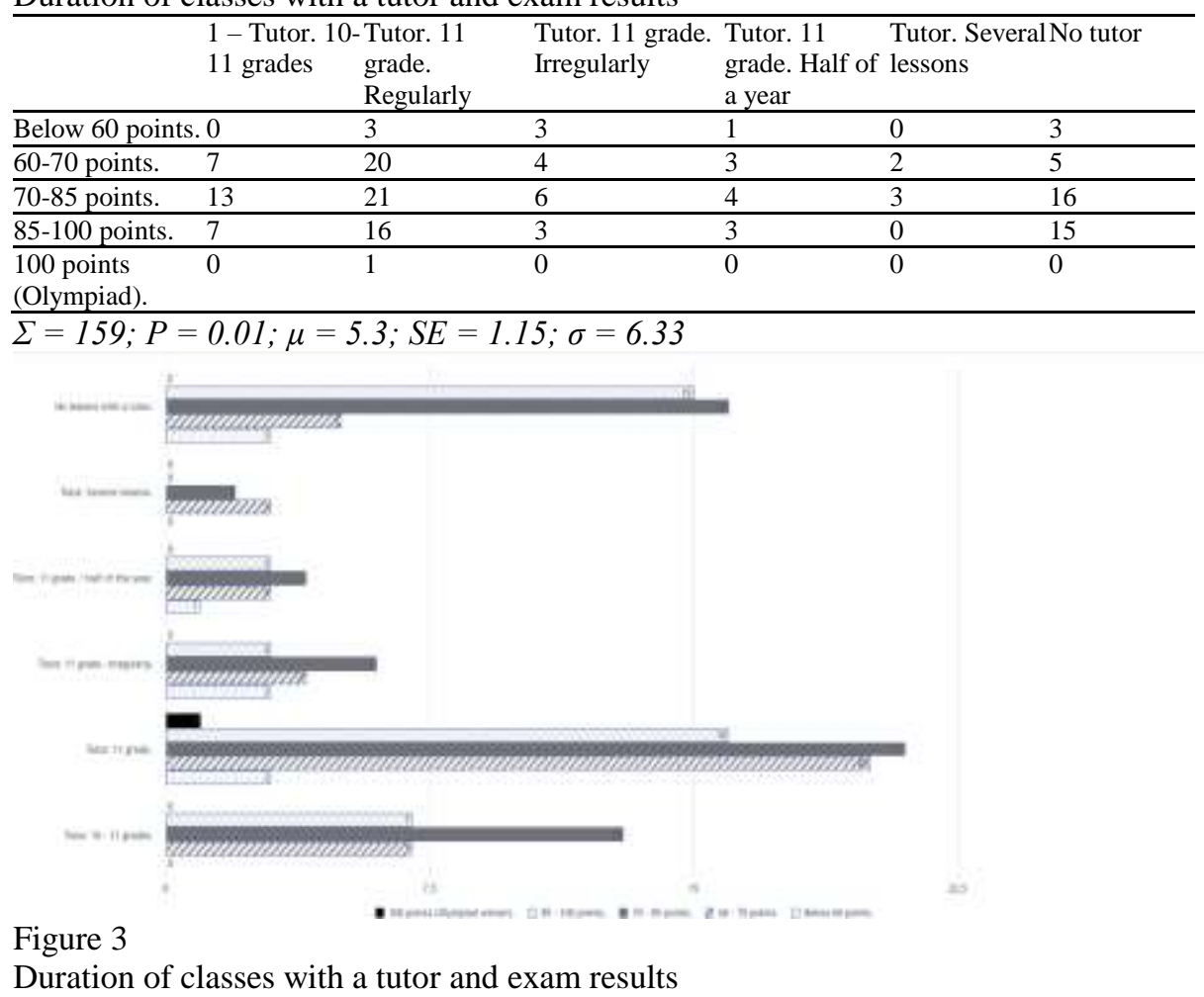

Graduates of the resource center "Sechenov Pre-University", medical classes in Moscow schools, working in the framework of the Pre-University program, as well as students from academic classes, teaching in which had been carried out according to specially developed programs entered I.M. Sechenov First Moscow State Medical University. Moreover, the University enrolled students who had studied in classes with a different (not biological) specialization or who had studied in ordinary secondary school.

As shown by the survey, regardless of which class the applicant was in, the classes with a tutor turned out to be preferable for the overwhelming majority. 120 respondents of the $159(0.75)$ somehow used the services of a tutor, and $39(0.25)$ did not work with a tutor. These data confirmed the assumption that tutoring played an important role in the individual educational strategy. In addition, it could be assumed that students chose individual classes, regardless of the class specialization they studied in (up to the Resource center "Moscow Pre-University") because the tutor: a) was able to provide additional knowledge and teach material that goes beyond the school curriculum and $b$ ) tutoring was a kind of "insurance" even in the case of training in a specialized academic class or in the Pre-University (Table 4). 
Table 4

Private lessons with a tutor. Different class specializations

\begin{tabular}{llll}
\hline & $\begin{array}{l}\text { Moscow Pre-University / Academic biological class The class of other } \\
\text { medical class in Moscow } \\
\text { school }\end{array}$ & \multicolumn{1}{c}{$\begin{array}{l}\text { specialization / class } \\
\text { without specialization }\end{array}$} \\
\hline Studied with a tutor & 25 & 37 & 58 \\
\hline $\begin{array}{l}\text { Was not engaged with a } \\
\text { tutor }\end{array}$ & 18 & 13 \\
\hline$\Sigma=159 ; P=0.6 ; \mu=26.5 ; S E=7.5 ; \sigma=18.4 ; r=0.36$ &
\end{tabular}

The ratio between students who studied with a tutor and those who did not use the services of private teachers, regarding class specialization was as follows:

- Sechenov Pre-University / Moscow medical class - 25:8 (3.13)

- Academic class - 37:18 (2.06)

- Class without profile orientation - 58:13 (4.7)

At the same time, the analysis of the average exam results of graduates of classes with different specialization did not reveal significant differences. The average score (on a five-point scale) in all three cases was about 3 (from 2.8 to 3.2). Thus, graduates of the Sechenov Pre-University (Moscow medical class) showed an average score of 3.2. Graduates of academic biological classes, as well as graduates of academic classes of other specialization and non-specialized classes showed the same average score -2.8 .

The system of calculating the average score was as follows:

1 point - USE results below 60 points,

2 points - USE $60-70$ points,

3 points - USE $70-85$ points,

4 points - USE $85-100$ points,

5 points - the winner of the Olympiad $(100+$ points $)$.

The data are shown in the Figure 4.

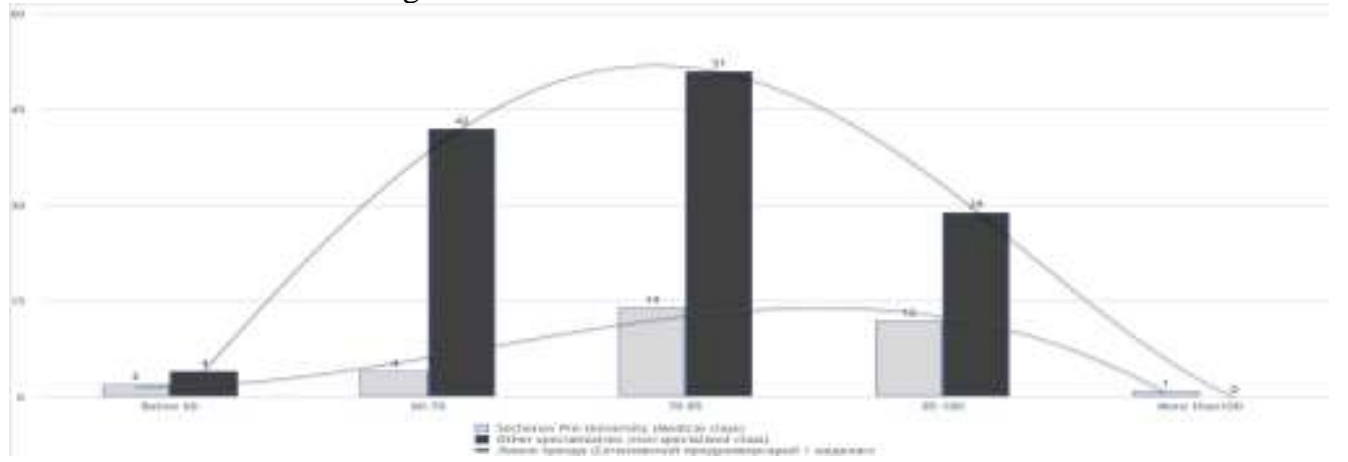

Figure 4

Class specialization and the results of the USE 
The OX: the number of points for the USE, the OY: the number of people in the group (the groups are indicated above).

It was worth noting that an evident (though a small) shift towards higher scores on the Unified State Exam (3.2 to 2.8) among graduates of the Sechenov Pre-University or medical classes working in the Pre-University program with respect to graduates of academic biological classes (classes with a different specialization / without specialization) was confirmed by the trend lines in the diagram.

There was a particular interest in the results of USE applicants who, in implementing their individual educational strategies, did not use the services of a tutor. Among the respondents, 39 of first-year students $(24.5 \%)$ were not engaged with a tutor. Summarized data on the results of the Unified State Examination are presented in Table 5.

Table 5

Exam results in biology (without the help of a tutor)

\begin{tabular}{lllll}
\hline & Less than 60 points & $60-70$ points & $70-85$ points & $85-100$ points \\
\hline $\begin{array}{l}\text { Pre-University / } \\
\text { medical class }\end{array}$ & 0 & $1(0.125)$ & $3(0.375)$ & $4(0.5)$ \\
\hline $\begin{array}{l}\text { Academic class / class } \\
\text { without specialization }\end{array}$ & $3(0.1)$ & $4(0.13)$ & $13(0.42)$ & $11(0.35)$ \\
\hline$\Sigma=39 \cdot P=0.5 ; \mu=4.9 \cdot S E=1.6 ; \sigma=4.6$. & &
\end{tabular}

$\Sigma=39 \cdot P=0.5 \cdot \mu=4.9 ; S E=1.6 \cdot \sigma=4.6$

In this case the correlation value is significant: $\mathbf{r}=\mathbf{0 . 9 1 4}$. In case of $\mathrm{P}=0.5$, it could be assumed that regardless of the class in which the applicant studied, helshe was able to successfully pass the USE and entered the University without using the services of private teachers.

However, a generalized analysis of the effectiveness of the Unified State Exam among applicants who studied with a tutor and among those who chose not to use private lessons in the implementation of an individual educational strategy gave an obvious negative correlation: $\mathbf{r}=\mathbf{- 0 . 1 4 9}$. The analysis of the generalized results showed that during the preparation for entering the university the most common IES of highschoolers who became first-year students of the I.M. Sechenov First Moscow State Medical University were, respectively:

- Classes with a tutor during 11 grade + training in the class of another (not medical or chemical-biological) profile -19 people.

- Classes with a tutor during 11 grade + training in the class without any profile $-\mathbf{1 6}$ people.

- Classes with a tutor during 11 grade + training in a class with a chemical biological / academic profile -16 people.

- Training in a class with a chemical-biological / academic profile without the involvement of a tutor $-\mathbf{1 8}$ people. 
In total, 10 individual educational strategies were identified. For each strategy the average score of the exam was calculated. The results are presented in Table 6.

Table 6

The average score on the exam for each type of IES

\begin{tabular}{lll}
\hline Individual educational strategy & Number of students & Average exam score \\
\hline $\begin{array}{l}\text { 1. Sechenov pre-University (medical class in Moscow } \\
\text { school) / tutor for 1 year }\end{array}$ & 11 & $70-85$ \\
\hline 2. Class without profile/ tutor for 1 year & 16 & $60-70$ \\
\hline 3. Academic (chemical-biological class) / tutor for 1 year & 16 & $70-85$ \\
\hline 4. Other profile class / tutor for 1 year & 19 & $70-85$ \\
\hline 5. Class without profile / without a tutor & 5 & $70-85$ \\
\hline 6. Sechenov pre-University (medical class in Moscow & 8 & $70-85$ \\
school) / without a tutor & & \\
\hline 7. Other profile class / without a tutor & 9 & $70-85$ \\
\hline 8. Academic (chemical-biological) class / without a tutor & 18 & $70-85$ \\
\hline 9. Classes with a tutor for 2 years & 26 & $70-85$ \\
\hline 10. Classes for half a year / irregular classes / several lessons 31 & $60-70$ \\
\hline
\end{tabular}

The last two educational strategies were deliberately not divided into smaller ones (basing on the profile of the class), as we considered it necessary to compare the effectiveness of classes with a tutor basing on their duration: 2 years (10-11 grades), 1 year (11 grade), as well as irregular / single / semi-annual classes.

The results of the cluster analysis of the generalized data are presented below (Figure 5).

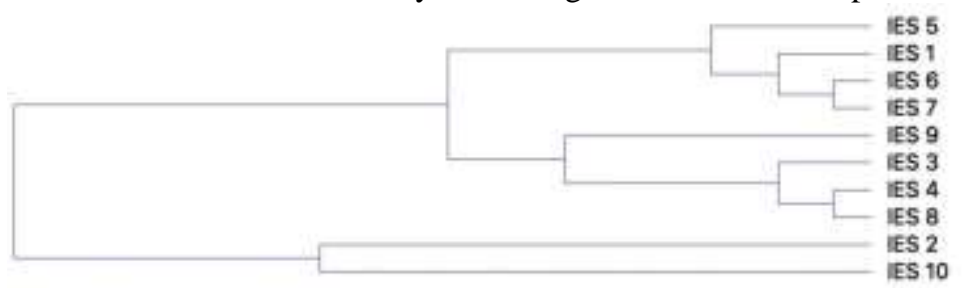

Figure 5

Clusters of individual educational strategies. Note: IES 1 - Sechenov pre-University (medical class in Moscow school) / tutor for 1 year; IES 2 - Class without profile/ tutor for 1 year; IES 3 - Academic (chemical-biological class) / tutor for 1 year; IES 4 Class of other profile / tutor for 1 year; IES 5 - Class without profile / without tutor; IES 6 - Moscow pre-University (medical class in Moscow school) / without tutor; IES 7 Other profile class / without a tutor; IES 8 - Academic (chemical-biological) class / without tutor; IES 9 - Tutoring for 2 years; IES 10 - Classes for half a year / irregular classes / several lessons

\section{DISCUSSION}

Indirectly, the high degree of the world community interest in this matter can be shown by a large review that gives the results of basic up-to-date data studies as well as suggests a number of recommendations for building further work (Bray, 2013). However, most researchers focus on the economic component of the issue, while this study is mainly aimed not at studying the general impact on the economy after 
implementation of certain components in the educational practice, such as tutoring or preparatory courses, which is an analogue of the educational franchise, but it is aimed at the effectiveness evaluation of these components for each applicant. This topic is considered in relation to the practice in Hong Kong (Kwok, 2009), Korea and Bangladesh (Hamid et al., 2009; Jung \& Lee, 2010; Lee et al., 2010). Some authors reveal the question of economic context even more fully and consider not only a simple individual tutoring as a separate sector of the economy, but also the provision of such educational services through the Internet, which in their opinion increases the possibility of academic mobility without physical movement between different regions (Ventura \& Jang, 2010). Such a view is fundamental and important; however, particular issues that ultimately interest applicants and their parents often remain unconsidered. In the works devoted to the actual effectiveness of tutoring or other additional educational components the authors do not come to agreement. Different variants of shadow education in Korea are considered and the author comes to the conclusion that the addition of such strategies gives a small increase in the quality of education. However, the use of additional schools which are an analogue of pre-entry courses in Russia, led to a more significant increase in academic performance than other forms of additional education. The author explains it by the fact that these additional schools follow the curriculum more strictly, without deviating from the school course. The successes of students in Mathematics were compared, achievements of 7,000 students were analysed. The majority of respondents (5047 students) considered tutors to be more effective in terms of training than regular school teachers. At the same time, the performed data analysis shows a much more diverse picture (Yung, 2020). In this study, it was demonstrated that classes with a tutor, regardless of the term, but always regular, lead to positive results when entering the university. These data can be explained, among other things, by the high responsibility of the student who regularly works with a tutor. Similar conclusions are supported by colleagues who have studied this issue in Germany (Guill \& Lintorf, 2019).

In addition, the vast majority of studies are devoted to training in subjects of humanitarian orientation, as a rule, we are talking about learning English. At the same time, works devoted to the study of other subjects (such as Mathematics) still occur. For example, one of the publications considers tutoring in three subjects at once: English, Chinese and Mathematics. The author comes to complex conclusions that do not allow giving an unambiguous answer for all categories of applicants, but finds correlations between the success of additional education included in the educational strategy and the quality of general education, comparing urban and rural schools (Zhang, 2013). While working with data and analysing sources, no strategies similar to ours were found. In addition, there are no researches on educational strategies in Biology which could be compared to our survey. It is important to note that there is a distinct interest to this topic nowadays. In particular, the issues of biological education composition in high school and various pedagogical methods aimed at improving student outcomes are discussed (Iancu, 2015). However, the author did not set the task to study educational strategies for university admission, while our study allows us to look at biology teaching in this context. The authors hope that this work will expose the issue in more details. 


\section{CONCLUSION}

Based on the questionnaire data analysis it could be asserted that neither classes with a tutor, nor training in specialized classes could not guarantee high scores of the Unified State Exam and admission to the selected university. Taking into account $\mathrm{P}=0.5$, it can be assumed that regardless of the class in which the applicant studied, helshe is able to successfully pass the USE and enter the University without using the services of private teachers.

Two questionnaires of our study that showed the highest score on the exam and admission to the university on the basis of the Olympiad results were an indirect confirmation of this assumption. Respondents also indicated that they were not engaged with a tutor and studied in ordinary secondary schools without any "profile".

At the same time, basing on the results of the study it could also be assumed that at the moment the most optimal was the IES in which regular classes with a tutor supplemented the school curriculum in biology, regardless of the presence or absence of an appropriate profile. The generalized data confirmed our idea that those graduates who were regularly engaged with a tutor, regardless of the "profile" of the class in high school, received a relatively high exam score. This fact could serve as a confirmation that classes with a tutor were really an effective tool in the preparation of the applicant.

Interestingly, the implementation of the IES "Sechenov Pre-University (medical class in Moscow school) / classes with a tutor in 11 grade" did not give serious advantages in admission that could be expressed in the expected higher exam scores. This was probably due to the fact that the standard program of preparation for the exam with a tutor was completely overlapped, duplicated by the program of biology in the PreUniversity (medical class). As a result, the student studying with a tutor did not receive additional knowledge that could significantly improve the results of the exam.

It was also important to pay attention to the two strategies that showed minimal results: "Class without profile/ tutor for 1 year" and "Classes for half a year / irregular classes / several lessons". Students who chose these IES showed lower exam results. At the same time, it was necessary to take into account the fact that the last strategy united all possible options of "class profile", including medical classes in Moscow schools and Sechenov Pre-university.

It could be assumed that the lower results of the exam in the implementation of the strategy "Class without a profile / tutor for 1 year" were explained by the initially low training level of the student at the moment of transition (admission) to the final grade.

Further studies that will include an assessment of the current academic level of applicants will allow verifying the correctness of this hypothesis. It is possible that the lower average USE results in the framework of implementation of the IES "Classes for half a year / irregular classes / several lessons" may be associated with a low level of current motivation and interest of students and their parents in the result of the Unified State Exam. 
The study of applicants' motivation is beyond the scope of this paper. Taking into consideration the results obtained in the present work it might have a decisive impact on the results of the USE and entrance exams and hence is a subject for future research.

\section{REFERENCES}

Bray, M. (2013). Shadow education: Comparative perspectives on the expansion and implications of private supplementary tutoring., Procedia - Social and Behavioral Sciences , 77, 412-420.

Bray, M. (2014). The impact of shadow education on student academic achievement: Why the research is inconclusive and what can be done about it. Asia Pacific Education Review, 15(3), 381-389.

Buchmann, C., Condron, D. J. \& Roscigno, V. J. (2010). Shadow education, American style: Test preparation, the SAT and college enrollment. Social Forces, 89(2), 435-461.

Burdyak, A. Y. (2015). Additional classes in school subjects: motivation and prevalence. Monitoring of Public Opinion: Economic and Social Changes, 2(125), 9112.

Byun, S.-Y. (2014). Shadow education and academic success in Republic of Korea. In: Park, H. \& Kim, K. (Eds), Korean education in changing economic and demographic contexts. Singapore: Springer, pp. 39-58.

Chan, V. N. M. (2019). English Private Tutoring in Macao: Perceptions of Senior Secondary Three Students. ECNU Review of Education, 2(1), 44-63.

Entrich, S. R. (2017). Shadow education and social inequalities in Japan: Evolving patterns and conceptual implications. Singapore: Springer.

Edumarket.digital research (2016). Available at: http://files.runetid.com/2017/rif/presentations/19apr.rif17-2.3--dreval.pdf. Last assessed on 12 May 2020.

Gallagher, J. A. (2017). Towards better choices and improved practice: A study of the influences on students' course and college choice in Ireland. Dissertation, University of Glasgow.

Guill, K. \& Lintorf, K. (2019). Private tutoring when stakes are high: Insights from the transition from primary to secondary school in Germany. International Journal of Educational Development, 65, 172-182.

Hamid, M. O., Sussex, R. \& Khan, A. (2009). Private tutoring in English for secondary school students in Bangladesh. Tesol Quarterly, 43(2), 281-308.

Iancu, M. (2015). The Scientific Research "Identification of Factors that Influence Pupils' Attitudes and Opinions Regarding the Study of Biological Disciplines. Procedia - Social and Behavioral Sciences, 180, 612-619. 
Jung, J. H. \& Lee, K. H. (2010). The determinants of private tutoring participation and attendant expenditures in Korea. Asia Pacific Education Review, 11(2), 159-168.

Kostina, L. A. \& Milyaeva, L. M. (2014). Socio-psychological adaptation of students to study in medical school. Fundamental Research, 1, 1-11.

Kuan, P.-Y. (2011). Effects of cram schooling on mathematics performance: Evidence from junior high students in Taiwan. Comparative Education Review, 55(3), 342-368.

Kwok, L. Y. (2009). A cultural analysis of cram schools in Hong Kong: impact on youth values and implications. Journal of Youth Studies, 12(1), 104-114.

Lee, C. J., Lee, H. \& Jang, H.-M. (2010). The history of policy responses to shadow education in South Korea: Implications for the next cycle of policy responses. Asia Pacific Education Review, 11(1), 97-108.

Loyalka, P. K. \& Zakharov, A. (2016). Does shadow education help students prepare for college? International Journal of Educational Development, 49, 22-30.

Nath, S. R. (2008). Private supplementary tutoring among primary students in Bangladesh. Educational Studies, 34(1), 55-72.

Naumova, A. A. (2017). The role of tutoring in the modern education system. In Russia between modernization and archaization: 1917-2017, Materials of the XX All-Russian Scientific and Practical Conference in 2 volumes. ANOVO Gumanitarnyj Universitet. Surgut, pp. 385-390.

Nurieva, L. M. \& Kiselev, S. G. (2018). Put in a good word about a tutor (again about the effectiveness of tutoring in USE preparation). Education and Science, 20(8), 148163.

Pivovarov, Yu. P., Dagaeva, Z. A. \& Sheina, N. I. (2015). The study of the lifestyle of students of medical and biological classes in Moscow. Public Health and Habitat, 264(3), 13-15.

Silova, I. \& Bray, M. (2006). The hidden marketplace: Private tutoring in former socialist countries. In Silova, I., Bray, M., Zabulionis, A., Budiene, V. \& Kubánová, M. (Eds), Education in a hidden marketplace: Monitoring of private tutoring. Budapest: Education Support Program (ESP) of the Open Society Institute, pp. 71-98.

Smyth, E. (2009). Buying your way into college? Private tuition and the transition to higher education in Ireland. Oxford Review of Education, 35(1), 1-22.

Spiridonova, E. V., and N. V. Melikhova. "Analysis of the Knowledge Level of University Entrants and Ways to Improve It." International Scientific Conference" Far East Con"(ISCFEC 2018). Atlantis Press, 2019.

Vasilyeva, I. V. (2016). Problems of development of the system of core and pre-profile education to prepare schoolchildren for professional orientation in the context of new labour market demands Advances in Modern Science and Education, 1(5), 18-21. 
Ventura, A. \& Jang, S. (2010). Private tutoring through the internet: Globalization and offshoring. Asia Pacific Education Review, 11(1), 59-68.

Yung, K. W. H. (2020). Comparing the effectiveness of cram school tutors and schoolteachers: A critical analysis of students' perceptions. International Journal of Educational Development, 72, 102141.

Zhang, Y. (2013). Does private tutoring improve students' National College Entrance Exam performance? A case study from Jinan, China. Economics of Education Review, $32,1-28$.

Appendix

Survey questionnaire

Your Faculty:

1) General Medicine

2) Dental

3) Public Health

Where did you graduate from high school?

1) I graduated from high school in Moscow

2) I graduated from high school in other Russian city

3) I graduated from high school in a regional center / town $\square$

4) I graduated from high school in a settlement / a village

5) I graduated from high school abroad $\square$

Did you study in high school with a medical or biological specialization?

1) I studied in Sechenov Pre-University / "Medical class in Moscow School"

2) I studied in a class of biological specialization / of academic specialization

3) I studied in a class of other specialization

4) I studied in a standard class without any specialization

How many Biology classes did you have per week?
1) 1 class
2) 2 classes
3) 3 classes
4) 4 classes
5) 5 classes
6) More then 5 classes

How often did you have Biology laboratory classes?

1) One class per week

1) One class per month $\square$

2) One class in half a year

3) One class per year

4) I had no laboratory classes

\section{Choose the truest statement:}

1) In the $11^{\text {th }}$ grade, we worked with tests more often than studied Biology

2) In the $11^{\text {th }}$ grade, we worked with tests no more than $30 \%$ of the total class time

3) In the $11^{\text {th }}$ grade, we studied Biology and worked with tests occasionally 
4) In the $11^{\text {th }}$ grade, we worked with tests rarely / from time to time

5) In the $11^{\text {th }}$ grade we were hardly taught Biology

Your U.S.E. score (no extra points):

1) Less than 60

2) $60-70 \square$

3) $70-85$

4) $85-100$

5) I got 100 U.S.E. points as a winner of Olympiad or any other intellectual competition $\square$

Choose the truest statement:

1) I experience difficulty mastering special biological terminology

2) I experience difficulty assimilating the volume of training material in biology

3) I have difficulty during tests/colloquiums/recitations

4) I experience difficulty being prepared for laboratory classes

5) I have no difficulty with Biology course at the University

Did you have classes with a private tutor before entering the University?

1) I had regular classes more than 2 year $\square$

2) I had regular classes in the $11^{\text {th }}$ grade

3) I had irregular classes in the $11^{\text {th }}$ grade

4) I had regular classes during the half a year before entering the University

5) I had several classes with a private tutor

6) I had no private classes

How often did you get classes with a private tutor ( 1 academic hour - 45 minutes)?

1) Once per week, one academic hour $\square$

2) Once per week, two academic hours

3) Two classes per week, one academic hour

4) Two classes per week, two academic hours

5) More than two classes per week

How were you taught (trained) by a private tutor?

1) Generally, we worked with U.S.E tests

2) Generally, we worked with tests but some topics were being explained in written form $\square$

3) I had typical classes with a private tutor. Sometimes we also worked with U.S.E. tests $\square$

4) I had typical classes with a private tutor. There were no tests at all 